\title{
Optimization of antioxidant extraction from Persicaria barbata leaves using response surface methodology (RSM)
}

\author{
P. Jaroennoni ${ }^{1}$, P. Sithisarn ${ }^{2}$, P. Rojsanga ${ }^{{ }^{*}}$ \\ ${ }^{1}$ Department of Pharmaceutical Chemistry, Faculty of Pharmacy, Mahidol University, Bangkok, \\ 10400, Thailand. \\ ${ }^{2}$ Department of Pharmacognosy, Faculty of Pharmacy, Mahidol University, Bangkok, 10400, \\ Thailand.
}

\begin{abstract}
Optimization of antioxidant capacity from Persicaria barbata leaf extract was conducted using response surface methodology (RSM). The conditions investigated were $90-150 \mathrm{~min}$ extraction time $\left(x_{1}\right), 60-75 \% \mathrm{v} / \mathrm{v}$ ethanol concentration $\left(x_{2}\right)$ and $30-50 \mathrm{v} / \mathrm{w}$ liquid-to-solid ratio $\left(x_{3}\right)$ while a fixed extraction temperature at $95^{\circ} \mathrm{C}$ was chosen. The quality of fit to the second-order polynomial models was confirmed based on the coefficient of determination of 0.9581 . Box-Behnken experimental design indicated that models can significantly $(p<0.05)$ express more than $80 \%(>0.80)$ of the response variation. The order of factors influencing the response value of antioxidant capacity was ethanol concentration, extraction time and liquid-to-solid ratio, respectively. The optimal extract condition for maximum antioxidant capacity was $120 \mathrm{~min}$ of extraction time, $60 \%(\mathrm{v} / \mathrm{v})$ of ethanol concentration, $40: 1 \mathrm{~mL} / \mathrm{g}$ of liquid-to-solid ratio and extraction temperature at $95{ }^{\circ} \mathrm{C}$. The ascorbic acid equivalent antioxidant capacity (AEAC) value obtained from experiment was $93.825 \pm 0.15 \mathrm{mg}$ $\mathrm{AEAC} / \mathrm{g}$ of dried plant.
\end{abstract}

Keyword: Persicaria barbata, response surface methodology, antioxidant capacity

\section{INTRODUCTION}

Recently, there has been an increased interest about natural fruits and vegetables consuming to improve health-promoting mechanisms in human body. In Thai traditional medicines, some fruits and vegetables have been used as sources of phytochemicals to treat various illnesses. These plants contain many components such as vitamins, minerals, carotenoids and polyphenols which could act as natural antioxidants. It is well known that antioxidants are beneficial to human health due to their abilities to reduce free radicals that can cause the damages of biomolecules ${ }^{1-3}$. Numerous clinical studies have confirmed that antioxidant phytochemicals can prevent various chronic and degenerative diseases such as cardiovascular diseases, various cancers, diabetes and obesity ${ }^{4,5}$. Persicaria barbata (L.) H. Hara var. barbata (Polygonaceae) is commonly known in Thai as Pakpod ${ }^{6}$. It is a perennial herb that grows widely in marshy and aquatic places, the sides of the rivers in Thailand, India, Nepal, Australia, and also in many other countries in the south-east Asia ${ }^{7}$. Decoction of leaves and shoots is used as a stimulating wash for ulcers, acting as a good healer of the scarred tissue ${ }^{7}$. In our previous study has shown that the leaf extract of $P$. barbata possessed high antioxidant capabilities tested by the thiobarbituric acid reactive substances (TBARS) method and contain a high total of phenolic and total flavonoid contents determined by the Fast Blue BB and aluminum chloride methods, respectively ${ }^{8}$. The efficiency of the extraction of antioxidants from plant source is influenced by multiple parameters such as extraction temperature, time and the liquid-tosolid ratio, among others, and their effects may be either independent or inter-active. In order to overcome this problem, when many factors affect desired variables, response surface methodology (RSM) is an effective tool for optimizing the process $^{9-11}$. In RSM, mathematical and statistical 
techniques are collected for designing experiments, building models, evaluating the effects of factors and searching optimum condition of factors for desirable responses ${ }^{9}$.It has been successfully reported that RSM using Box-Behnken design can be used to optimize the extraction conditions from plants to obtain active compounds ${ }^{9,12}$. No such study has been carried out on the extraction of antioxidants from $P$. barbata leaves. In present study, the antioxidant capacity was considered as response value while extraction time, ethanol concentration, liquid to solid ratio and extraction temperature were considered for optimization parameters. Box-Behnken design was employed to optimize the process parameters of antioxidant extraction from the P. barbata leaves.

\section{MATERIALS AND METHODS}

\subsection{Plant material and sample preparation}

P. barbata leaf was collected from Wang Nam Yen district, Sa Kaeo province, Thailand, during May - July 2012 and was identified by comparing to the herbariums at the office of the Forest Herbarium, Ministry of natural resources and environment, Bangkok, Thailand. The sample was cleaned and dried in a hot air oven (Memmert, U.S.A.) at $60{ }^{\circ} \mathrm{C}$ for $6-8$ hours. The dried sample was ground and passed through a sieve with mesh number 20 .

\subsection{Extraction of antioxidants}

To select independent variable, the single factors for extraction procedures were set as follows. Firstly, the effect of extraction time was investigated. The sample powder was mixed with $40 \mathrm{~mL}$ of $45 \%(\mathrm{v} / \mathrm{v})$ ethanol and boiled at different times (30, 60, 90, 120, 150 minute) at $85^{\circ} \mathrm{C}$. Secondly, the effect of ethanol concentration was studied. The sample powder was mixed with $40 \mathrm{~mL}$ of different ethanol concentrations $(30,45,60,75,90 \%$ ethanol, v/v) and boiled for 30 minute at $85^{\circ} \mathrm{C}$. Thirdly, the effect of liquid to solid ratio was varied. Different volume of $45 \%(\mathrm{v} / \mathrm{v})$ ethanol $(10,20,30,40$, $50 \mathrm{~mL}$ ) was added with the sample powder and boiled for 30 minute at $85{ }^{\circ} \mathrm{C}$. Lastly, the effect of extraction temperature was performed. $40 \mathrm{~mL}$ of $45 \%(\mathrm{v} / \mathrm{v})$ ethanol was mixed with the sample powder and boiled for 30 minute at different temperature $\left(75,80,85,90,95^{\circ} \mathrm{C}\right)$. After centrifuged, the supernatant was diluted 500 times with solvent $(30,45,60,75,90 \%$ ethanol).

The extraction procedure of the experiment in a Box-Behnken design was set as follows. One gram of $P$. barbata leaf powder was mixed with different concentrations of ethanol-water $(60,75,90 \%$ ethanol) and different liquid to solid ratio $(30,40,50 \mathrm{~mL})$, then put in water bath for refluxing at constant temperature $\left(95^{\circ} \mathrm{C}\right)$ as well as boiled for different time (90, 120, 150 minute) depend on each experimental design (Table 1). After centrifuged, the supernatant was diluted 200 times with solvent $(60,75,90 \%$ ethanol)

Table 1. Coded and actual levels of three variables

\begin{tabular}{lrrr}
\hline \multirow{2}{*}{ Variables } & \multicolumn{3}{c}{ Coded levels of variables } \\
\cline { 2 - 4 } & -1 & 0 & 1 \\
\hline Extraction time $\left(x_{1}\right)$ & 90 & 120 & 150 \\
Ethanol concentration $\left(x_{2}\right)$ & 60 & 75 & 90 \\
Liquid to solid ratio $\left(x_{3}\right)$ & 30 & 40 & 50 \\
\hline
\end{tabular}

Each experiment was carried out in triplicate. All of the extract solutions were centrifuged at 4,500 rpm for $15 \mathrm{~min}$. The supernatant of each experiment was collected for evaluation of the antioxidant capacity using DPPH radical scavenging method. One gram of $P$. barbata leaf powder was weighed to use in each experiment. 


\subsection{Determination of antioxidant capacity using DPPH radical scavenging method}

The method was slightly modified from Thomas $\mathrm{J}$ Heraldet $\mathrm{al}^{13}$. The ascorbic acid standards at the concentration of $2-14 \mu \mathrm{g} / \mathrm{mL}$ were prepared in distilled water and use for the calibration curve of ascorbic acid (Sigma-Aldrich, U.S.A). Five milliliters of either working standard or sample solutions was mixed with $5-\mathrm{mL}$ of $208 \mu \mathrm{M}$ DPPH (Sigma-Aldrich, U.S.A) in methanol (Burdick \& Jackson, Korea). After kept the standard and sample in dark for 40 minutes, the absorbance was measured at $515 \mathrm{~nm}$ using an UV-Visible spectrophotometer (Shimadzu, Japan). Each standard and sample extract was analyzed in triplicate. The percentage of inhibition (\%inhibition) was calculated as follow equation below and was related to the concentration of ascorbic acid standard curve. The result was expressed as average mg ascorbic acid equivalent antioxidant capacity per gram dried plant (mg AEAC/g of dry plant $\pm \mathrm{SD})$.

$$
\% \text { inhibition }=\frac{A_{\text {control }}-A_{\text {sample }}}{A_{\text {control }}} \times 100
$$

Whereas $\mathrm{A}_{\text {control }}$ is absorbance of control $(5 \mathrm{~mL}$ methanol $+5 \mathrm{~mL} \mathrm{DPPH})$ and $\mathrm{B}_{\text {sample }}$ is absorbance of sample $(5 \mathrm{~mL}$ sample solution + $5 \mathrm{~mL}$ DPPH).

\subsection{Experimental design}

The influence of extraction factors were optimized using Response Surface Methodology (RSM). A Box-Behnken experimental design was used to investigate the effects of three independent variables, namely extraction time $\left(\min ; x_{1}\right)$, ethanol concentration $\left(\% \mathrm{v} / \mathrm{v} ; x_{2}\right)$ and liquid-to-solid ratio $\left(\mathrm{v} / \mathrm{w} ; x_{3}\right)$. Three levels of each variable were coded as $-1,0$ and +1 based on the results of preliminary single factor experiments according to the following equation.

$$
\mathrm{X}=\left(X_{1}-X_{0}\right) / \Delta X
$$

When $X$ is the code value, $X_{l}$ is the corresponding actual value, $X_{0}$ is the actual value in the center of the domain and $\Delta X$ is the increment of $X_{1}$ corresponding to a variable of 1 unit of $X$. The experimental design consists of 12 factorial experiments and three replicates of the central point giving in Table 2. Ascorbic acid equivalent antioxidant capacity (AEAC) was selected as the responses for the combination of the independent variables using DPPH radical scavenging method. Experiment run were randomized, to minimize the effects of unexpected variability in the observed responses.

A second-order polynomial regression model was used to express the yield as a function of independent variable as follows.

\begin{tabular}{|c|c|c|c|c|}
\hline \multirow{2}{*}{ No } & \multicolumn{3}{|c|}{ Coded levels of variables } & \multirow{2}{*}{$\begin{array}{c}\text { DPPH } \\
\text { (mg AEAC/g dried plant) }\end{array}$} \\
\hline & $\chi_{1}$ & $\chi_{2}$ & $\chi_{3}$ & \\
\hline 1 & -1 & -1 & 0 & $78.29 \pm 3.58$ \\
\hline 2 & -1 & 1 & 0 & $49.61 \pm 1.88$ \\
\hline 3 & 0 & -1 & 1 & $93.3 \pm 2.11$ \\
\hline 4 & 0 & 1 & 1 & $65.21 \pm 7.58$ \\
\hline 5 & 0 & -1 & -1 & $92.79 \pm 3.63$ \\
\hline 6 & 1 & 1 & 0 & $67.31 \pm 3.80$ \\
\hline 7 & 1 & 0 & -1 & $89.45 \pm 15.36$ \\
\hline 8 & -1 & 0 & 1 & $83.39 \pm 13.83$ \\
\hline 9 & -1 & 0 & -1 & $71.11 \pm 1.79$ \\
\hline 10 & 1 & -1 & 0 & $88.59 \pm 8.14$ \\
\hline 11 & 0 & 1 & -1 & $52.49 \pm 0.90$ \\
\hline 12 & 1 & 0 & 1 & $76.74 \pm 2.69$ \\
\hline 13 & 0 & 0 & 0 & $79.6 \pm 1.69$ \\
\hline 14 & 0 & 0 & 0 & $80.56 \pm 3.63$ \\
\hline 15 & 0 & 0 & 0 & $77.5 \pm 2.29$ \\
\hline
\end{tabular}

Table 2. Experimental designs using Box-Behnken and results 


$$
y=\beta_{0}+\sum_{i=1}^{3} \beta i X_{i}+\sum_{i=1}^{3} \beta_{i i} X_{i}^{2}+\sum_{i=1}^{2} \sum_{j=1+1}^{3} \beta_{i j} X_{i} X_{j}+\varepsilon
$$

When $y$ represents the response variables (DPPH), $\beta o$ is the model constant, $\beta i$, $\beta i i, \beta i j$ are the linear, quadratic and interactive coefficients, respectively, $x_{i}, x_{j}$ is the levels of the independent variables and $\varepsilon$ is the error.

Analysis of the Box-Behnken design data was carried out using Design Expert software (Version 7.0.0). Additional confirmation experiments were subsequently conducted to verify the validity of the statistical experimental design.

\section{RESULTS AND DISCUSSION}

\subsection{Evaluations of single extracting factors on antioxidant capacity of $P$. barbata leaf extract}

\subsubsection{Effect of extraction time}

The effect of extraction times on antioxidant capacity of $P$. barbata leaf extract was shown in Figure 1 (A). Extraction was carried out at different times (30 - $150 \mathrm{~min}$ ) while other extraction parameters were kept constant $(45 \%$ ethanol, 40:1 liquid-to-solid ratio and $85^{\circ} \mathrm{C}$ extraction temperature). When the time increased from 30 to $120 \mathrm{~min}$, the AEAC significantly increased from $43.82 \pm 16.72$ to $100.08 \pm$ $16.73 \mathrm{mg}$ AEAC/ $\mathrm{g}$ of dried plant. However, the AEAC no longer changed when the extracting time continuously increased.

\subsubsection{Effect of ethanol concentration}

The concentration of extraction solvent is a variable that influences efficiency of extraction to obtain high antioxidant capacity extract. Most of the phytochemical antioxidant compounds are phenolics and flavonoids. Ethanol is a suitable solvent for extraction of phenolics and flavonoids due to its universal extracting capacity. Generally lower ethanol concentration is appropriate for the extraction of polar flavonoid compounds and higher ethanol concentration is appropriate for the extraction of non-polar flavonoid compounds.
The effect of ethanol concentration on antioxidant capacity of $P$. barbata leaf extract was shown in Figure 1 (B). Extraction was carried out at different concentration of ethanol (30 $90 \%, \mathrm{v} / \mathrm{v}$ ) while other extraction parameters were kept constant (40:1 liquid-to-solid ratio, $85^{\circ} \mathrm{C}$ extraction temperature and 30 min extraction time). When the concentration of ethanol increased from 30 to $45 \%$, the AEAC increased from $70.72 \pm 5.17$ to $77.41 \pm 35.02 \mathrm{mg} \mathrm{AEAC/}$ $\mathrm{g}$ of dried plant. Whereas, the AEAC of the $60 \%$ of ethanolic extract decreased to $54.67 \pm$ $23.81 \mathrm{mg}$ AEAC/ $\mathrm{g}$ of dried plant. The ethanol concentration increased to $75 \%$, the AEAC was significantly increased to $88.28 \pm 7.95$ mg AEAC/ g of dry plant. Nevertheless, the AEAC decreased to $25.02 \pm 5.93 \mathrm{mg} \mathrm{AEAC} / \mathrm{g}$ of dried plant, as the concentration of ethanol increased to $90 \%$.

\subsubsection{Effect of liquid-to-solid ratio}

The effect of liquid-to-solid ratio on the antioxidant capacity of $P$. barbata leaf extract was shown in Figure $1(\mathrm{C})$. Extraction was carried out at different liquid-to-solid ratio $(10-50, \mathrm{v} / \mathrm{w})$ while other extraction parameters were kept constant $\left(45 \%\right.$ ethanol, $85^{\circ} \mathrm{C}$ extraction temperature and $30 \mathrm{~min}$ extraction time). The AEAC significantly increased from $38.26 \pm$ 12.09 to $158.89 \pm 83.82 \mathrm{mg} \mathrm{AEAC/g}$ of dried plant as the liquid-to-solid ratio with in the range of $10-40(\mathrm{v} / \mathrm{w})$. Whereas the liquid-to-solid ratio increased to $50(\mathrm{v} / \mathrm{w})$, the AEAC decreased to $90.16 \pm 19.79 \mathrm{mg}$ AEAC/ $\mathrm{g}$ of dried plant. It may be due to the increase of driving force to improve the mass transfer of antioxidant compound.

\subsubsection{Effect of extraction temperature}

Extraction temperature is a variable that can promote extraction of antioxidant compound by enhancing the diffusion coefficient and solubility of antioxidant compounds in plants. 


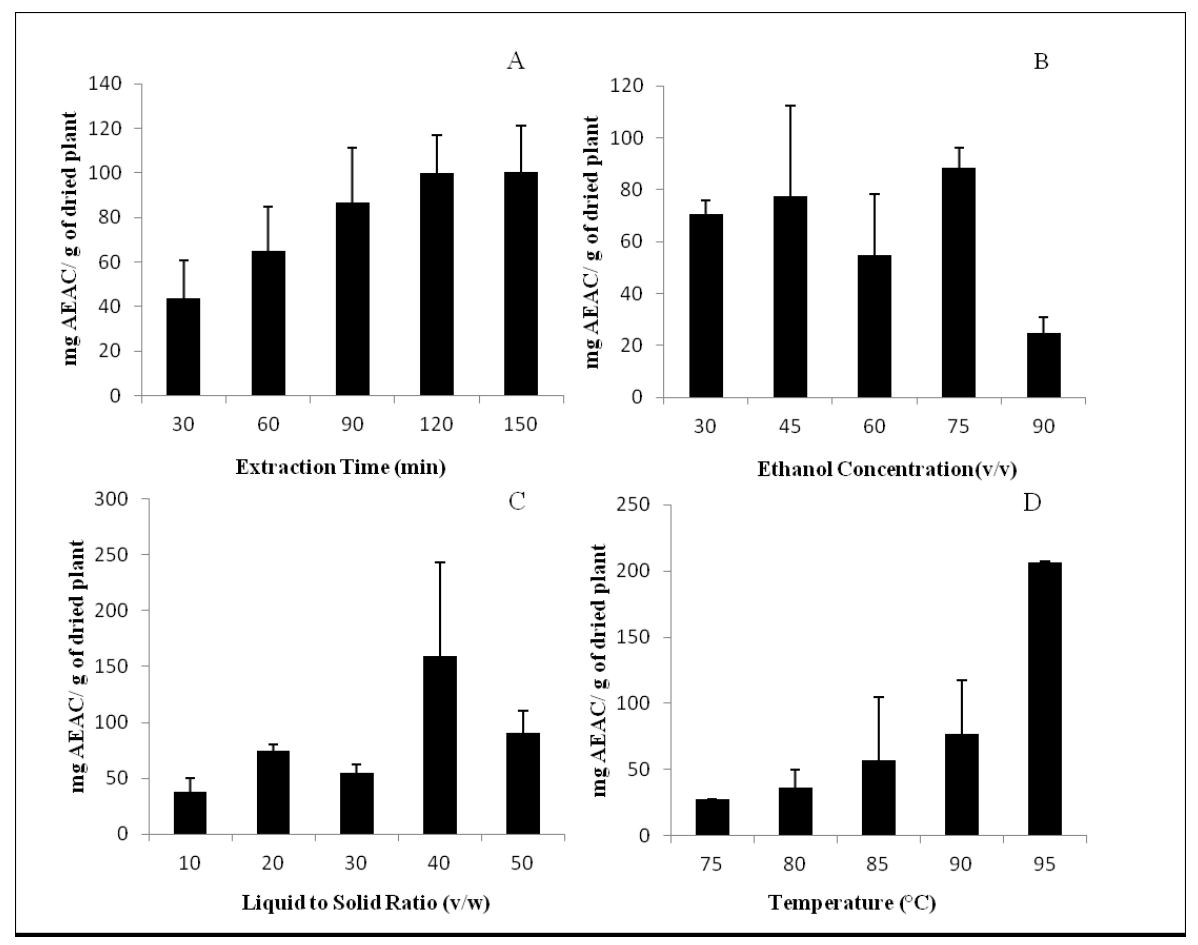

Figure 1. The effects of extraction factors on antioxidant capacity using DPPH method expressed as mg AEAC/g of dried plant; (A) extraction time, min; (B) ethanol concentration, $\mathrm{v} / \mathrm{v}$; (C) liquid to solid ratio, $\mathrm{v} / \mathrm{w}$; (D) extraction temperature, $\mathrm{C}^{\circ}$

The effect of extraction temperature on antioxidant capacity of $P$. barbata leaf extract is shown in Figure 1 (D). Extraction was carried out at different extraction temperatures $(75$ $95^{\circ} \mathrm{C}$ ) while other extraction parameters were kept constant (45\% ethanol, 40:1 liquid-to-solid ratio and 30 min extraction time). The AEAC significantly increased from $27.57 \pm 0.42$ to $206.13 \pm 1.31 \mathrm{mg} \mathrm{AEAC/g}$ of dried plant as the extraction temperature increased from 75 to $95^{\circ} \mathrm{C}$.

From the results of single factor, Extraction time ( $\left.\mathrm{x}_{1} ; 90,120,150 \mathrm{~min}\right)$, ethanol concentration $\left(\mathrm{x}_{2} ; 60,75,90 \%\right)$ and liquid-tosolid ratio $\left(\mathrm{x}_{3} ; 30,40,50 \mathrm{v} / \mathrm{w}\right)$ were determined as the independent variables and a fixed extraction temperature $\left(95^{\circ} \mathrm{C}\right)$ was selected.

\subsection{Optimization of $P$. barbata leaf extraction method}

The extraction of $P$. barbata on antioxidant capacity using DPPH radical scavenging method was further optimized through the RSM approach (Box-Behnken design). The coded and actual levels of the three variables in Table 1 were chosen to maximize the AEAC value. From the results of single factor, the maximum AEAC of each factor was defined as the center of domain $\left(\chi_{0}\right)$. The actual level of $-1,0$ and 1 were calculated as described in section 2.4. Table 2 presented the treatments with coded levels of variables and experimental results of AEAC in P. barbata leaves. Fifteen experiments were designated, which $1-12$ were factorial experiments and $13-15$ were zeropoint tests performed to estimate the errors. The treatments with coded levels and ranged from $49.61 \pm 1.88$ to $92.79 \pm 3.63 \mathrm{mg} \mathrm{AEAC} / \mathrm{g}$ dried plant. The highest of AEAC value $(92.79 \pm 3.63)$ was obtained under experiment condition of $=120 \mathrm{~min},=60 \%$ and $=30 \mathrm{v} / \mathrm{w}$.

\subsubsection{Establishment of quadratic regression equation}

By applying multiple regression analysis on the experimental data, the response variable 
(AEAC) and the test variable are related by the following polynomial equation (in term of coded factors):

$$
\begin{aligned}
\mathrm{y}= & 79.22+4.96 \chi_{1}-14.79 \chi_{2}+1.6 \chi_{3}+1.85 \chi_{1} \chi_{2}- \\
& 6.25 \chi_{1} \chi_{3}+3.05 \chi_{2} \chi_{3}-2.02 \chi_{1}^{2}-6.25 \chi_{2}^{2}+2.97 \chi_{3}^{2}
\end{aligned}
$$

The analysis of variance (ANOVA) for the regression equation by Design Expert Software 7.0 was presented in Table 3. The quality of fit to the second-order polynomial models was confirmed based on the coefficient of determination $(=0.9581)$. The result indicated that models can significantly $(p<0.05)$ express more than $80 \%(>0.80)$ of the response variation. The lack of fit $(p>0.05)$ was not significant suggesting that the model was suitable to represent the actual situation, reflecting the relationship between the antioxidant capacity and extraction parameters. In addition, the obtained regression equation can predict well the extraction condition for high antioxidant capacity. The terms of $\chi_{1}(p=0.0275), \chi_{1}(p=0.0003), \chi_{1} \chi_{3}(p=0.0408)$, $\chi_{2}^{2}(p=0.0464)$ were significant indicating that the relationship between response variable (antioxidant capacity; AEAC) and the test variable was not linear (Table 3 ).

Table 3. Analysis of variance (ANOVA) for the regression equation

\begin{tabular}{ccccccc}
\hline SD & SS & DF & MS & F value & Prob $>F$ & S \\
\hline Model & 2375.73 & 9 & 263.97 & 12.70 & 0.0060 & $*$ \\
$\chi_{1}$ & 196.91 & 1 & 196.91 & 9.47 & 0.0275 & $*$ \\
$\chi_{2}$ & 1750.84 & 1 & 1750.84 & 84.23 & 0.0003 & $* *$ \\
$\chi_{3}$ & 20.48 & 1 & 20.48 & 0.99 & 0.3665 & \\
$\chi_{1} \chi_{2}$ & 13.69 & 1 & 13.69 & 0.66 & 0.4539 & \\
$\chi_{1} \chi_{3}$ & 156.13 & 1 & 156.13 & 7.51 & 0.0408 & $*$ \\
$\chi_{2} \chi_{3}$ & 37.27 & 1 & 37.27 & 1.80 & 0.2382 & \\
$\chi_{1}^{2}$ & 15.10 & 1 & 15.10 & 0.73 & 0.4329 & \\
$\chi_{2}^{2}$ & 144.12 & 1 & 144.12 & 6.93 & 0.0464 & $*$ \\
$\chi_{3}^{2}$ & 32.68 & 1 & 32.68 & 1.57 & 0.2653 & \\
Residual & 103.93 & 5 & 20.79 & & & \\
Lack of Fit & 99.03 & 3 & 33.01 & 13.48 & 0.07 & not significant \\
Pure Error & 4.90 & 2 & 2.45 & & & \\
Cor Total & 2479.664 & 14 & & & & \\
\hline
\end{tabular}

SD: soure of deviation; SS: sum of squares; DF: degree of freedom; MS: mean squre;

S: significant; $* p=0.05, * * p=0.01$

\subsubsection{The analysis of RSM}

Thee-dimensional response surface plots and two-dimensional contour plots are presented in Figure $2 \mathrm{~A}-\mathrm{C}$. These types of plots refected the effects of two factors on the response value at a temperature. The other factors were not showed in each figure as level zero (40:1 Liquidto-solid ratio, $75 \%$ ethanol concentration, $120 \mathrm{~min}$ extraction time). In Figure 2 (A), the AEAC increased when extraction time $\left(\chi_{1}\right)$ increased. However, the AEAC decreased when ethanol concentration $\left(\chi_{2}\right)$ increased. The effects of ethanol concentration had a more significant effect on the AEAC than extraction time in the selected range. The AEAC increased when extraction time $\left(\chi_{1}\right)$ and liquid-to-solid ratio $\left(\chi_{3}\right)$ increased (Figure 2 (B)). Figure 2 (C) showed that an increase of liquid-to-solid ratio $\left(\chi_{3}\right)$ 
resulted in an initial increase of AEAC and decreased when liquid-to-solid ratio continuously increased. While, the AEAC increased when ethanol concentration $\left(\chi_{2}\right)$ decreased. The result suggessed that the order of factors influencing the response value of antioxidant capacity was as follow: ethanol concentration $\left(\chi_{2}\right)>$ extraction time $\left(\chi_{1}\right)>$ liquid-to-solid ratio $\left(\chi_{3}\right)$. The maximum response value was obtained inside the experimental region showing in response surface plots and contour plots as the red area.

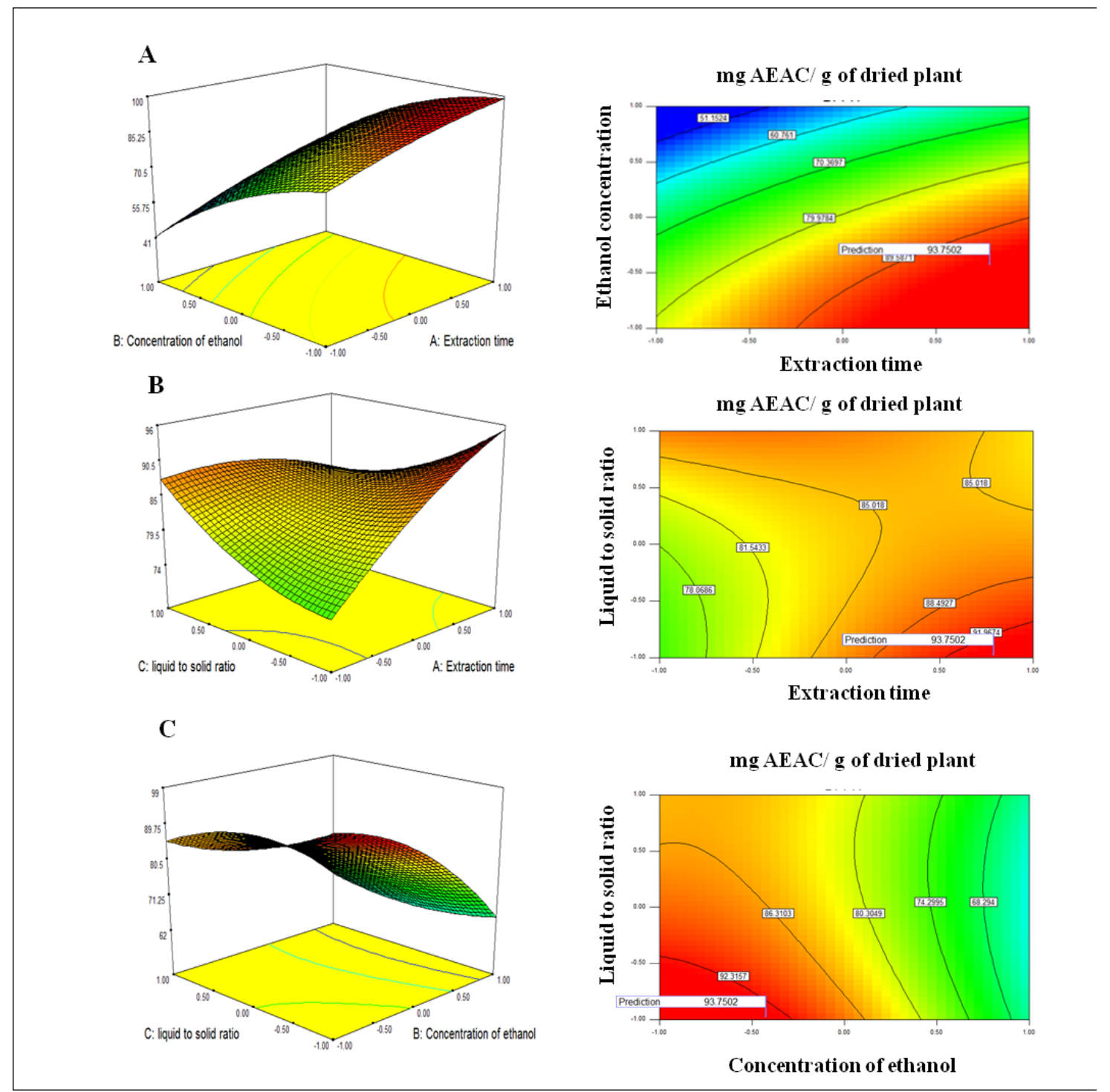

Figure 2. Three-dimensional and two-dimensional contour plots of antioxidant capacity (A) Response plot of extraction time $\left(\chi_{1}\right)$ vs. concentration of ethanol $\left(\chi_{2}\right)$; (B) Response plot of extraction time $\left(\chi_{1}\right)$ vs. liquid-to-solid ratio $\left(\chi_{3}\right)$; (C) Response plot of concentration of ethanol $\left(\chi_{2}\right)$ vs. liquid-to-solid ratio $\left(\chi_{3}\right)$

\subsubsection{Verification of predicted value of the models}

The optimal value of the selected factors obtained by Design Expert software were extraction time $=101.38(\mathrm{~min})$, ethanol concentration $=60.18 \%(\mathrm{v} / \mathrm{v})$, liquid-to-solid ratio $=47.27(\mathrm{~mL} / \mathrm{g})$ with the predicted value 
of AEAC as $93.75 \mathrm{mg} \mathrm{AEAC/g}$ of dried plant. To verify the obtained model, the experiment was caried out under the appropriately adjusted condition as following, 120 min of extraction time, $60 \%(\mathrm{v} / \mathrm{v})$ of ethanol concentration, 40 : $1 \mathrm{~mL} / \mathrm{g}$ of liquid-to-solid ratio and extraction temperature at $95^{\circ} \mathrm{C}$. The AEAC value obtained from experiment $(93.825 \pm 0.15 \mathrm{mg} \mathrm{AEAC} / \mathrm{g}$ of dried plant) was closed to the predicted value from optimized condition.

\section{CONCLUSION}

The response surface methodology (RSM) was used to optimize the extraction of antioxidant capacity from $P$. barbata leaf using Box-Behnken experimental design. Ethanol concentration was the most an influence factor of extraction, while the temperature was limited at $95^{\circ} \mathrm{C}$. The optimal condition was an extraction by $60 \%(\mathrm{v} / \mathrm{v})$ ethanol, liquid-to-solid ratio of $40 \mathrm{~mL} / \mathrm{g}$ and extraction temperature at $95{ }^{\circ} \mathrm{C}$ for $120 \mathrm{~min}$.

\section{ACKNOWLEDGEMENTS}

This work was financially supported by the National Research Council of Thailand.

\section{REFERENCES}

1. Mayur B, Shruti S,Seo SY. Antioxidant and $\alpha$-glucosidase inhibitory properties of Carpesium abrotanoides L. J Med Plants Res. 2010;4:1547-53.

2. Cheng Z, Moore J, Yu L. High-throughput relative DPPH radical scavenging capacity assay. J Agric Food Chem. 2006;54:742936.

3. Gan RY, Kuang L, Xu XR, Zhang Y, Xia EQ, Song FL, et al. Screening of natural antioxidants from traditional Chinese medicinal plants associated with treatment of rheumatic disease. Molecules. 2010;15: 5988-97.

4. Aaby K, Hvattum E, Skrede G. Analysis of flavonoids and other phenolic compounds using high-performance liquid chromatography with coulometric array detection: relationship to antioxidant activity. J Agric Food Chem. 2004; 52: 4595-603.
5. Xu Z, Howard LR. Analysis of antioxidantrich phytochemicals. Wiley-Blackwell. Noida. 2012:1-69.

6. Kantachot C, Chantanothai P, Simpson DA. A synopsis of the genus Persicaria (Polygonaceae) in Thailand. Thai Forest Bull (BOT). 2010;38:128-149.

7. Choudhary RK, Ali MA, Lee J. Studies on genetic diversity among populations of Persicaria barbata (L.) H. Hara from India based on internal transcribed spacer sequences of nuclear ribosomal DNA. Saudi J Biol Sci. 2011;18(2):123-7.

8. Jaroennon P, Sithisarn P, Buranaphalin S, Rojsanga P. Inhibition of lipid peroxidation by Thai edible plants and their phenolic and flavonoid contents. Proceeding in the $8^{\text {th }}$ Indochina Conference on Pharmaceutical Sciences; 2013 Dec 4-5;Ho Chi Minh City, Vietnam.

9. Liu W, Yu Y, Yang R, Wan C, Xu B, Cao S. Optimization of total flavonoid compound extraction from Gynura medica leaf using response surface methodology and chemical composition analysis. Int J Mol Sci. 2010; 11:4750-63.

10. Bae H, Jayaprakasha GK, Jifon J, Patil BS. Extraction efficiency and validation of an HPLC method for flavonoid analysis in peppers. Food Chem. 2012;130(3):751-8.

11. Khajeh M. Optimization of microwaveassisted extraction procedure for zinc and copper determination in food samples by Box-Behnken design. J Food Comp Anal. 2009;22:343-6.

12. Kaiser S, Verza SG, Moraes RC, Pittol V, Penaloza EMC, Pavei C, et al. Extraction optimization of polyphenols, oxindole alkaloids and quinovic acid glycosides from cat's claw bark by Box-Behnken design. Ind Crops Prod. 2013;48:15361.

13. Herald TJ, Gadgil P, Tilley M. Highthroughput micro plate assays for screening flavonoid content and DPPH-scavenging activity in sorghum bran and flour. J Sci Food Agr. 2012;92(11):2326-31. 